\title{
Ficção e realidade no programa Cidade dos Homens: elementos para pensar sobre mídia e pedagogia das imagens ${ }^{*}$
}

\section{Fiction and reality in the Cidade dos Homens TV program: elements to think about media and image pedagogy}

\author{
Suzana Feldens Schwertner**
}

\begin{abstract}
RESUMO
O presente artigo discute as relações entre ficção e realidade num programa de TV e suas implicações para a educação. Expõe resultados de uma investigação em que, entre outros objetivos, procurou-se investigar acerca da autenticidade das imagens na "sociedade do espetáculo", destacando a profusão de "imagens caseiras" em produtos televisivos contemporâneos. Para tanto, estuda algumas cenas da microssérie Cidade dos Homens, veiculada pela Rede Globo entre 2002 e 2004. A análise da estrutura do programa, sua sintaxe e formas de narrar permitiram expor formas de visibilidade dos efeitos de realidade no seriado. As conclusões apontam para a utilização de recursos próprios dos programas de caráter documental, como a utilização de "cenas caseiras" e de depoimentos em "tempo real", na busca por uma autenticidade das imagens. Enfatiza-se, ao final, que estudos sobre a mídia televisiva implicam sempre uma posição ética e política e, assim, tornam-se tarefa fundamental na educação ética e estética dos sujeitos.

Palavras-chave: televisão, realidade, ficção, linguagem televisiva.
\end{abstract}

* Agência financiadora $\mathrm{CNPq}$

** Psicóloga, mestre em educação pela Universidade Federal do Rio Grande do Sul (UFRGS).

E.mail:suzifs@uol.com.br 


\begin{abstract}
This article discusses the relations between fiction and reality on a TV program and its implications to education. It shows the results of an investigation in which, among other goals, it was aimed to investigate the authenticity of the images in the "society of the spectacle", emphasizing the profusion of "home-produced images" in contemporary television series. It studies some scenes of Cidade dos Homens, presented by Rede Globo from 2002 until 2004. The analysis of the program structure, syntax and narrative forms allowed exposing the visibility ways of the reality effects in the series. The conclusions point to the utilization of the very resources of programs with documentary characteristics, like "homeproduced scenes" and "real time" testimonies, searching for images authenticity. By the end it emphasizes that studies about TV media always imply an ethical and political position, therefore becoming a fundamental task on subject's ethical and aesthetic education.

Key-words: television, reality, fiction, television language.
\end{abstract}

Discutir sobre televisão, seus processos, seus programas e seus produtores, deveria ser atividade inerente ao pesquisador preocupado com as relações entre mídia e educação. O espaço ocupado pela televisão na atualidade excedeu em muito o lugar de entretenimento ou informação que a princípio lhe era delegado. Hoje, para além de um locus pedagógico, a "telinha" (que pode ser grande, pequena, enorme, plana, de cristal líquido) propõe formas de desejar, apresenta modelos de identidade, assegura companhia durante as 24 horas do dia para crianças, jovens e adultos. A já famosa "babá eletrônica" segue firme em sua tarefa de entreter e, juntamente com esta função, acaba também por configurar novas formas de sociabilidade (KEHL, 2004).

A escolha por trabalhar com imagens, analisar programas da mídia televisiva, não ocorre de forma neutra - como ainda fantasiam alguns pesquisadores. As imagens que escolhemos para análise não são meras imagens; fazem parte da nossa história, mobilizam-nos, seja por nos tocarem e nos surpreenderem, seja por nos chocarem. Pesquisar televisão é investigar um acontecimento do qual também faço parte: assistir à televisão é um hábito rotineiro, ao qual me entrego como a maioria dos telespectadores. De que forma problematizar, a partir de estudos, teorias, análises de programas, algo que é tão presente e cotidiano? Segundo Rosa Fischer (2001), a análise de imagens dos produtos televisivos deve ser detalhadamente investigada, o 
pesquisador de mídia necessita mergulhar nas imagens e formular problematizações a partir delas:

Eleger a TV como material de estudo na educação tem também este sentido, de ir além, além de nossas cotidianas e mínimas ações sobre as imagens, mas sempre respeitando-as, partindo delas, a fim de dinamizar e multiplicar o vivido, experimentar com fruição e pensamento todos esses artefatos culturais que olhamos e que nos olham (FISCHER, 2001, p. 53-54).

Trata-se de transformar os produtos televisivos em “... documentos para fruição, investigação e pensamento" (FISCHER, 2001, p. 57). Podemos, assim, desenvolver uma discussão sobre a televisão e pensar nesse outro espaço ocupado pela TV, o de criador de linguagem e de formas de mostrar e visibilizar determinados acontecimentos. Há que se atentar para a produção de determinados sentidos a partir da linguagem televisiva, atentar para a construção de um certo tipo de formas de falar que produz algo no telespectador. Se pensarmos mais especificamente no programa Cidade dos Homens, perguntamos de que forma se fala nesse produto televisivo sobre a realidade brasileira? A microssérie de ficção, elaborada em conjunto pela produtora $\mathrm{O} 2$ e pela Rede Globo de Televisão, foi baseada no sucesso do longa-metragem Cidade de Deus e trata da história de dois meninos negros (Acerola e Laranjinha), moradores de uma favela do Rio de Janeiro. Veiculado entre os anos de 2002 e 2004 pela Rede Globo, o programa selecionado surpreende pelas passagens sensíveis, que abordam compromissos de solidariedade, convivência, cuidado com o outro. E também choca ao nos mostrar esses pontos sensíveis em meio à violência urbana, ao tráfico de drogas, à exclusão social e racial, assuntos pungentes e urgentes na sociedade brasileira contemporânea.

Neste texto, ${ }^{1}$ procuramos investigar acerca da autenticidade das imagens na "sociedade do espetáculo", destacando a profusão de "imagens caseiras" nos programas de televisão. Para tanto, recorremos a autores como Susan Sontag e Guy Debord para discutir sobre uma possível necessidade de inserção de "cenas reais" nos programas, evidenciada na contemporaneidade. A

1 Este trabalho tem como ponto de partida minha pesquisa de mestrado, em que analisei nove episódios da microssérie Cidade dos Homens. Para maiores detalhes, consultar as referências. 
fim de falar "de dentro" das imagens, trazemos excertos da programação televisiva que apontam para imagens com efeito de realidade e analisamos mais detalhadamente cenas da microssérie Cidade dos Homens.

\section{Autenticidade das imagens: discussão entre real e ficção na socieda- de do espetáculo}

Em cada município constroem-se grandes casas em que as mentiras são reunidas e expostas, as chamadas bibliotecas. Poderíamos chamá-las também de "laboratórios de mentiras" ou coisa parecida. Mas o melhor de tudo talvez fosse chamar as bibliotecas de "depósitos de fatos e lorotas". É, pois nem tudo o que se diz nos livros é mentira. Podemos até mesmo encontrar no mesmo livro, lado a lado, a verdade e a pura fantasia, e às vezes é difícil distinguir o que é uma coisa e o que é outra. E também muitas coisas que são a mais pura verdade são tão inacreditáveis que parecem mentiras ou invenções malucas (GAARDER, J.; HAGERUP, K., 2003, p. 28).

No relato da personagem Berit Boyum, jovem norueguesa criada por Jostein Gaarder e Klaus Hagerup, há uma discussão muito presente na contemporaneidade e da qual é bastante difícil nos esquivarmos. Problematizar realidade e ficção, seja em imagens literárias, fotográficas, cinematográficas ou televisivas, torna-se um árduo trabalho. Definir limites detalhados entre um e outro pode se traduzir em uma tarefa quase impossível, pois, como destaca a personagem Berit, “... muitas coisas que são a mais pura verdade são tão inacreditáveis que parecem mentiras”. O que seria pura criação, invenção, "lorota"? E o que seria fato, acontecimento? De que forma o jogo entre realidade e ficção é retratado em pinturas, no cinema, na TV?

A pensadora Susan Sontag, faz-nos pensar na complicada trama entre realidade e ficção, estabelecendo relações com nossa reação "diante da dor dos outros". Ao analisar fotografias sobre guerras, mortos combatentes, soldados fuzilados, corpos e paisagens destroçados, pergunta-se como somos 
convocados, na atualidade, a reagir a tais imagens. Informa-nos que a partir da Guerra do Vietnã até os nossos dias (acrescento: ainda mais neles), fomos inundados por uma "teleintimidade com a morte e a destruição", transformando destruição em entretenimento. Segundo a autora, “... batalhas e massacres filmados no momento em que se desenrolam tornaram-se um ingrediente rotineiro do fluxo incessante de entretenimento televisivo doméstico" (sONTAG, 2003, p. 22). As guerras - conflitos políticos e territoriais - acabam por se transformar em espetáculos, uma espécie de show de horrores ou então como os snuff movies, ${ }^{2}$ filmes em que o cenário e as ações criados são "invadidos" pela realidade, com requintes de crueldade. A guerra, aquilo que está acontecendo em algum lugar do mundo, é transmitida ao vivo, como se fosse algo preparado para isso. Voltamos então ao imbróglio colocado inicialmente: isso é real ou ficcional?

A questão da autenticidade da imagem também é algo a problematizar. Sontag aponta para as discussões sobre a veracidade de uma fotografia de guerra, ao mostrar quantas fotos foram "montadas" pelos fotógrafos e mundialmente conhecidas como um "retrato dos horrores da guerra". A questão da "subjetividade do criador de imagens" é por ela revolvida: torna-se difícil pensar em uma imagem pura, apenas registrada neutramente, sem a posição daquele que, na verdade, a construiu - selecionou a cena, escolheu o ângulo, remeteu o "tiro"” a uma determinada direção: "Na fotografia de atrocidades, as pessoas querem o peso do testemunho sem a nódoa do talento artístico, tido como equivalente à insinceridade ou à mera trapaça" (sONTAG, 2003, p. 26). A imagem, para ser considerada como autêntica, precisa evocar algo do "natural", da simplicidade e do realismo; não pode lembrar uma montagem ou qualquer elaboração da luminosidade - ela precisa mostrar o que realmente "aconteceu", sem farsas.

Uma discussão muito recente na mídia internacional tem abordado a questão de uma certa "paixão pelo real" nas imagens televisivas: aponta-se o enorme destaque das imagens de cenas cotidianas, de imagens da "vida como ela é", que proliferam em todo o mundo. Torna-se incontestável a capacidade de essas imagens capturarem um público amplo, cada vez mais sedento por

2 Snuff movies são filmes pornográficos, repletos de cenas sado-masoquistas que culminam com a morte dos atores-personagens. Para maiores detalhes, ver ZIZEK, S. Bem-vindo ao deserto do Real. São Paulo: Boitempo, 2003.

3 Refiro-me aqui a uma brincadeira entre a tradução de shot do inglês para o português: verbo que serve para designar tanto o disparo de uma arma de fogo quanto para o disparo de uma foto ("tirar" ou "bater" uma foto, em português). 
programas que mostrem algo do comum, do banal, imagens em que possam reconhecer-se. Exemplos típicos dessa espécie de produção podem ser descritos pelas mais diversas formas de reality shows, apresentados nos mais diversos canais de televisão do mundo - sob as mais diversas roupagens. Programas que acompanham a vida de pessoas encerradas em uma casa, de personalidades que expõem sua vida familiar em 24 horas de convivência, de pessoas que se propõem a mudanças radicais em seus corpos e em seus comportamentos e que são capturadas nos mais íntimos espaços de sua vida. Shows da realidade: misto de realidade e ficção - cremos que muito mais ficção do que realidade -, mas entendidos como "a" realidade acima de tudo.

Ao analisar os nove episódios do programa Cidade dos Homens, deparamo-nos com um elemento da linguagem audiovisual que não pode ser ignorado e que remete à discussão que estamos realizando: a inserção de cenas "reais", gravadas em uma câmera que possui outro tipo de película, que nos passa a sensação de algo que aconteceu, que não foi "ficcionalmente construído", atestando uma certa veracidade. O que tais imagens vêm nos dizer sobre essa proclamada necessidade de cenas "reais", tais quais aquelas imagens de cinegrafista amador?

Este elemento da linguagem televisiva torna-se um dos pontos de análise do programa: a inserção de cenas "reais" na estrutura do melodrama. Como falar de questões pungentes e atuais da sociedade brasileira em um programa ficcional, sem incluir cenas da "vida real"? Em um dos episódios ("A Coroa do Imperador"), entremeado à história que é narrada, uma das cenas é filmada como se fosse por uma "câmera caseira": nela, os atores que interpretam os personagens na ficção conversam a respeito da violência na favela. São imagens chocantes, que falam de uma história real, com pessoas reais - quem fala ali são os meninos-atores, não os personagens -, que acontece todos os dias em favelas de grandes cidades como o Rio de Janeiro. Posteriormente, na próxima seção, vamos voltar a esse exemplo.

Há também inúmeras cenas, espécies de quadros do programa, que também podem ser caracterizadas como "imagens caseiras". Não envolvem personagens, e sim momentos da trama, em que tal recurso é utilizado. Como exemplo, citamos um capítulo em que Acerola, um dos protagonistas do programa (interpretado por Douglas Silva) está parado em uma rua da favela, olha para os casebres de madeira e vemos a imagem de esgoto a céu aberto, lixo acumulado em volta das ruas. Nesse momento, por uma fração de segundos, a imagem se torna "caseira" e uma ratazana aparece se equilibrando em meio ao lixo.

Definir ficção e realidade pode não ser uma tarefa das mais complica- 
das; no entanto, são tênues os limites que separam os elementos de realidade e os de ficção em uma produção televisiva. Falar em uma sociedade que parece ter uma necessidade de "cenas reais" e em uma "sociedade do espetáculo" parece não se constituir um discurso contraditório, e sim a face de uma mesma moeda.

Guy Debord (1997), a partir do referencial marxista, estabeleceu uma relação direta entre mídia, consumo e espetáculo, ao declarar que a convivência entre as pessoas na contemporaneidade passa por uma relação mediada por imagens. E destaca que convivemos em total dependência do espetáculo: necessitamos dele para sobreviver e para nos relacionarmos. $\mathrm{O}$ autor revela a primazia da relação econômica sobre a realidade social, acrescentando um incomum sentido à dicotomia ser versus ter. Para Debord, em nossas relações pessoais, ultrapassamos há muito a idéia do ser para o ter. O que importava e tinha valor era aquilo que se tinha, e não o que se era. Agora, defende o pensador, já se implodiu a própria idéia de posse como valor e valorizamos o que se parece ter: o fundamental é a aparência, a imagem. No percurso de ser para ter e, em seguida, de ter a parecer ter, a sociedade do espetáculo se concretiza.

Tudo se transforma em espetáculo mediado por imagens: a unidade que falta à vida acontece nas (e pelas) imagens. Somos convidados a participar do espetáculo, crer, apreciar, chamar por ele. Porém, com esta espetacularização da imagem, acaba por se perder a dimensão humana e singular dos sujeitos. A tese de Debord parte do princípio de que a sociedade do espetáculo separa o homem dele mesmo, desvinculando-o da sua história. Assim, a sociedade do espetáculo acontece no agora e se caracteriza pelo imediatismo, o que acaba por "economizar a experiência". Assim sendo, a necessidade do "real" se converte em imagem para a sociedade do espetáculo apreciar: eis a aproximação de pólos que, a princípio, pareciam tão distantes.

Slavoj Zizek, crítico esloveno, radicaliza a relação entre imagem e realidade, ratificando as questões levantadas por Debord: "Não foi a realidade que invadiu a nossa imagem: foi a imagem que invadiu e destruiu a nossa realidade (ou seja, as coordenadas simbólicas que determinam o que sentimos como realidade)" (ZIZEK, 2003, p. 31). 


\section{Diante da dor real dos outros: a favela na sala de estar}

A partir da discussão iniciada acima, passamos a pensar na questão propulsora desse tipo de linguagem - a "imagem caseira" - nos programas de televisão, mais propriamente no produto Cidade dos Homens. Ao assistirmos a um telejornal ou mesmo a um documentário em um canal de televisão, deparamo-nos com muitas imagens capturadas por câmeras em ação, que acompanham os acontecimentos do mundo "ao vivo" em um determinado momento. De alguma maneira, eles "aconteceram". Essas reportagens, porém, estão sempre incrementadas por efeitos como a sonorização, o corte mais brusco ou mais suave, às vezes quase imperceptível -, o close-up, as diferentes tomadas das câmeras, o que acaba por imprimir um toque melodramático em sua estrutura. Realidade com toques de ficção.

No momento em que nos acomodamos para assistir a um programa fictício, como uma telenovela ou uma minissérie - em que lemos frases como "essa produção é uma obra fictícia, qualquer semelhança com fatos ou pessoas reais é mera coincidência" -, estamos diante de uma trama construída, elaborada por um ou vários autores, que nos contam uma determinada história. Mas nela também verificamos uma irrupção do "mundo de fantasia", a partir de cenas que são ali inseridas e que parecem ser um "chamado à realidade", como que para mostrar que também ali não sabemos onde estamos. Fiç̧ão com mesclas de realidade.

As telenovelas exibidas em diversos canais do Brasil mostram-nos personagens da trama envolvidos em passeatas pela paz, campanha efetivamente realizada pela prefeitura da cidade do Rio de Janeiro; acompanham "ao vivo" uma cirurgia plástica realizada em uma jovem, que não é atriz, mas sim uma pessoa que foi chamada pela produção para submeter-se a mudanças no seu corpo e ser "monitorada" pelos telespectadores. A última novela veiculada pela Rede Globo compromete-se a mostrar o dia-a-dia dos deficientes visuais, apresentando algumas instituições que se responsabilizam pelos cuidados específicos, especialmente para crianças, além de incentivar as pesquisas com células-tronco. ${ }^{4}$

Paralelamente, os telejornais apresentam suas reportagens como uma forma de ficção: trilhas sonoras embalam o choro comovente de uma mãe

4 Falo aqui das novelas "Mulheres Apaixonadas" (Rede Globo), "Metamorfose" (Rede Record) e "América" (Rede Globo), respectivamente. 
que perdeu sua filha em um acidente, ao mesmo tempo em que uma câmera capta o olhar doloroso e a expressão sofrida daquela mulher. Ou, então, um carro tombado em uma estrada tem sua imagem multiplicada por cinco câmeras diferentes, incluindo uma tomada aérea: a cena é a mesma, mas a movimentação das câmeras, a sonorização e a iluminação transformam o acontecido em espetáculo.

Em relação à linguagem do programa Cidade dos Homens, há um ponto a destacar: apesar de ser originalmente um programa de ficção, em todos os capítulos do seriado (tanto do ano de 2002 quanto do de 2003, mais timidamente nos episódios do ano de 2004), chama atenção o fato de a trama ser entrecortada por imagens que destaquei como "imagens caseiras". Ou seja, imagens captadas por uma câmera amadora, que transmite cenas com a impressão de que são "ao vivo", de que estão acontecendo naquele momento, de improviso; enfim, uma cena que se afigura como "real" - e não mais como ficcional. Pensamos o quanto, neste seriado, justamente por tratar de assuntos tão urgentes em nosso país - como a pobreza, a miséria, a violência urbana, o tráfico de drogas, o preconceito racial -, parece ser necessário trazer um pouco do factual, de imagens mais "reais", para que tais acontecimentos não apareçam apenas como ficção. Consideramos não ser possível apresentar tais temáticas apenas em caráter ficcional, mas ser necessário inserir ali "toques" de realidade.

A própria denominação da emissora em relação ao gênero do programa caracteriza-o como uma ficção com mesclas de humor e realidade. E aqui "realidade" parece referir-se a um novo tipo de classificação de programas: Turma do Gueto ${ }^{5}$ também marca a presença da realidade, do cotidiano, propondo ali uma "viagem do televisor à rua". ${ }^{6}$ Em reportagem recente, a revista IstoÉ destaca a inédita produção de sitcoms brasileiros, que teriam como diferencial a presença de negros e pobres nos papéis principais, destacando que se trata de uma "comédia da vida real".

No programa Cidade dos Homens, há o uso intenso daquelas imagens acima citadas, que remetem a uma autenticidade comprovada pela qualidade da imagem: as cores são mais distorcidas (em um tom mais azulado), a ima-

5 Programa da Rede Record, lançado em 2000 e protagonizado por atores negros. Exibido em horário nobre, a série alcançou os mais altos números no IBOPE, constituindo-se um dos programas mais vistos naquela emissora, tanto no ano de seu lançamento quanto no ano subseqüente.

6 Informação retirada do site do programa: www.turmadogueto.com.br

7 Ver reportagem de Camilo Vanucchi na revista IstoÉ, 14/07/2004. 
gem é tremida, não há um foco bem definido, o zoom "brinca" entre um ângulo e outro. Constituem imagens caseiras, brincadeiras com a câmera: em um dos episódios ("Dois para Brasília", do ano de 2003), a dupla protagonista Acerola e Laranjinha recebe uma câmera de vídeo para filmar a entrega da carta de um presidiário ao presidente do Brasil. Todo o capítulo "brinca" com as imagens, remetendo ora a uma, ora a outra, e algumas vezes até confundindo os dois tipos de imagens: a do seriado (imagem mais organizada, produzida com uma técnica mais apurada, preocupada com os detalhes de zoom, closeup) e a da câmera dos meninos (imagem com a coloração menos nítida, tremida, do tipo "caseira"). Esse último tipo de imagem, talvez por ser mais imperfeita, sugere consigo uma idéia de ser mais espontânea e por isso mais "real".

É importante, contudo, destacar que as duas imagens recebem um tratamento cuidadoso e "pertencem" ao seriado, ou seja, trata-se de ficção em ambos os casos: nenhuma delas é uma imagem da realidade. O que acontece é a utilização de recursos diferentes, o que produz efeitos de uma imagem "suja", captada diretamente de uma situação "real" (aquela que denominei "imagem caseira"), e de uma imagem mais "límpida", assumidamente de ficção. Ambos os tipos de imagem configuram técnicas de narrativa de programas ficcionais.

Chegamos, assim, ao ponto de análise que mais interessa: por que, em uma produção do tipo ficção, torna-se importante inserir essas imagens "reais"? O que esse elemento de linguagem vem acrescentar à produção? Seria essa uma forma de trazer, conforme especificado no título desta seção, a favela para a sala de estar, sem maquiagens, sem truques, "a realidade como ela é"? Como já foi dito anteriormente, parece interessante notar o quanto esse "apelo ao real" e a "sociedade do espetáculo", apesar de promoverem idéias paradoxais - em um primeiro momento - podem ser entendidas como duas faces de uma mesma moeda. Tentaremos exemplificar isso com a cena citada anteriormente sobre os meninos-atores falando da violência nas suas vidas, no programa Cidade dos Homens.

Em certo momento do episódio "A coroa do imperador" (2002) - o primeiro da microssérie Cidade dos Homens-, Laranjinha e Acerola estão desesperados, pois precisam entregar um remédio para a avó de Laranjinha. Mas os traficantes não liberam o acesso à escada, que seria a única passagem para a casa da avó. Após inúmeras tentativas, os meninos resolvem ir até a casa de um de seus amigos, que mora ao pé do morro. Na casa do amigo, está reunido um grupo de meninos, todos jogando videogame - a TV é apresentada algumas vezes, na tela aparecem lutadores com armas de fogo, que atiram sem parar: fogo, sangue e mortes são a tônica da brincadeira. Uma voz em off 
grita: é a mãe do menino, que pede para ver a novela e ordena que os meninos desliguem o videogame. Eles colocam então em um telejornal - o Jornal Nacional - e as cenas mostram imagens de tanques se movimentando pelas ruas destruídas, e, em seguida o apresentador mostra a Faixa de Gaza em um mapa: momentos de confusão entre ficção e realidade. Ao mesmo tempo em que os personagens falam sobre a guerra que estão vivenciando no morro, eles vêem imagens da guerra entre árabes e judeus, assistem ao "piscinão de sangue" (como diz um dos garotos), achando que é uma reportagem de tiroteio na favela. As falas dos meninos se confundem com as imagens da TV: um menino conta que um amigo deles, "aquele que jogava futebol", morreu no tiroteio dessa tarde, e que a mãe dele ficou tão desesperada que quase arrancou os cabelos. Corte rápido: na TV, imagens de uma mulher coberta pela burka chorando copiosamente, abraçada ao corpo de um menino.

É a partir desse momento que as imagens "caseiras" aparecem: os meninos conversam entre eles sobre as mais violentas cenas que já presenciaram, inclusive a morte de parentes muito próximos. César Charlone (roteirista e também diretor de alguns capítulos da microssérie) destaca, ao falar sobre a gravação dessa cena, ${ }^{8}$ que lançou a idéia aos meninos e deixou a câmera ligada, filmando os depoimentos - já não mais dos personagens, mas dos atores. Trata-se de uma cena bastante confusa - pois muitos falam concomitantemente -, e, ao mesmo tempo, tocante: escutam-se os depoimentos desses meninos, devidamente identificados (por meio de nome, sobrenome, profissão e idade, respectivamente) falando sobre uma guerra que vivenciam no dia-a-dia. Reproduzo a seguir um trecho dessa cena: ${ }^{9}$

Embaixo da tela, aparece a legenda: Emerson Gomes, ator, 13 anos fala em tom sério: Nesse dia morreu três caras ao mesmo tempo. Ele tomou um só e ele caiu, os polícia mataram ele. Outro que morreu junto com ele tomou uma rajada na cara e saiu essa parte aqui toda do rosto dele (faz o contorno do rosto com o dedo indicador) e ele ficou sem nada dentro do caixão e aí tiveram que botar ele discosta.

Legenda: Douglas Silva, ator, 14 anos - rosto com expressão assustada, olhos arregalados: Eu já vi três, três, três defunto, mané, amarrado, boiando assim...

8 Os depoimentos dos roteiristas e diretores da microssérie aparecem na parte dos "extras" do DVD Cidade dos Homens 2002.

9 Nas transcrições, mantive o texto tal e qual foi enunciado, sem, portanto, proceder a correções gramaticais. 
Legenda: Robson Rocha, ator, 17 anos - mãos no rosto, expressão séria: $\mathrm{Na}$ minha frente, assim, eu tava na janela, o cara morreu ali na minha frente!

Legenda: Darlan Cunha, ator, 14 anos - fala mais calmamente, tristeza no olhar: E os polícia mandando tiro de bala de borracha, jogaram a bomba de gás na janela da minha tia, explodiu até o bujão de gás e aí o meu tio deitado lá em cima morreu todo queimado. (silêncio na cena)

Os meninos prestam esses depoimentos de uma forma bastante agitada, estão assustados, as expressões revelam olhos arregalados, bocas abertas, mãos que tomam a forma de um revólver que dispara sem parar. Mas convém ressaltar que essa cena, por mais que expresse a realidade, o que aconteceu naquele momento, também apresenta, paralelamente, "toques" de criação, de editoração, de organização; enfim, o toque do espetáculo. Notamos o quanto tal cena foi editada de forma a separar algumas falas confusas dos garotos: há a organização em torno de uma temática - de acontecimentos que vivenciaram, com seus familiares, a morte de várias pessoas pela criminalidade do tráfico; em seguida, mortes promovidas por policiais e uma edição dos vários momentos em que os meninos fazem uma sonoplastia dos tiros ("puf", "vum" "bum", "ba-ba-ba-ba") até os últimos depoimentos, que versam sobre a vontade de "se formar com o movimento", de "entrar pra boca e ser sinistro pra ter respeito no morro". Notamos como o recurso de "gravação ao vivo" parece atestar a veracidade daquelas imagens.

Na última cena, Douglas Silva, ator que representa o personagem Acerola no programa, responde acerca da vontade de virar traficante. A cena segue sendo apresentada no formato de "gravação caseira" e a conversa agora está mais centrada em torno da vida no tráfico. Por meio da simulação de uma gravação "ao vivo", os jovens personagens conversam, trocam idéias, concordam e também discordam do que os outros falam. Essa simulação da imagem "ao vivo", não deixa de ser uma estratégia discursiva que busca a simultaneidade da gravação:

Douglas, olhando para um dos meninos, fala em tom exaltado: Quem vai querer saber que você não é bandido?

Marcos, ao seu lado, concorda com Douglas: Nunca quer saber, irmão, nunca quer saber!

Marcos, sério, olhando para a câmera, close em seu rosto: Todo mundo já pensou isso na vida, brother, se falar que não, é mentira! (corte rápido) 
De um dia se revoltar, entrar pra boca e ser sinistro pra ter respeito no morro!

Robson fala em tom de proposição aos meninos: $\mathrm{O}$ tráfico poderia proibir menor de 15 anos.

Darlan olha para Robson e fala serenamente: Não, mas ele bota menor porque menor não é preso, brother!

Douglas, close no seu rosto, expressão séria, fala em tom exaltado: Pensando, que bom, vai crescer e vai ser dono do mundo inteiro, mas não vai ser porra nenhuma porque chega na hora, mané, nem dos 18 anos não passa...

Ao concluir o depoimento, a imagem que vemos já não é mais aquela que corresponde a uma "gravação caseira", mas sim a imagem do programa, dos meninos (atores? personagens?) sentados na sala, espalhados pelo sofá e pelo chão, assistindo à televisão e escutando o final do depoimento de Douglas Silva, voz que toma forma de eco. Ficamos com a impressão de que eles assistiam às suas próprias imagens e depoimentos. Um silêncio conclui a cena.

Realidade em forma de espetáculo? Espetáculo em forma de realidade? São questões que perpassam o debate na seção que intitulei "Diante da dor real dos outros: a favela na sala de estar". Tais questões não pretendem se traduzir em respostas, mas em inquietações, a partir das análises realizadas. Diante da dor dos outros: realidade com toques de ficção. A favela na sala de estar: ficção com mesclas de realidade.

Vimos neste artigo questões bastante específicas da linguagem da TV, principalmente um dos tipos de estrutura de linguagem em torno da qual se organiza o programa Cidade dos Homens. Destacamos recursos próprios aos programas de caráter documental, como a utilização de "cenas caseiras" na busca de uma autenticidade às imagens. Destacamos igualmente esse efeito de realidade que perpassa muitos produtos televisivos veiculados na contemporaneidade. O que essa linguagem televisiva produz de sentidos deixa novas perguntas para os trabalhos de pesquisa e para a própria prática pedagógica escolar. Ressaltamos também a produção de um discurso que quer se mostrar permanentemente no presente, incluindo lances de improvisação, do inesperado.

Todas essas inquietações levam em conta a importância de um trabalho que priorize a posição interrogativa do pesquisador (seja ele pedagogo, psicólogo, comunicador) que se proponha a enfatizar a experiência da mídia, a falar "de dentro" das imagens, analisar a linguagem e os efeitos de sentido ali produzidos. Somente assim seremos capazes de realizar um estudo 
comprometidamente ético e político que “... problematize nossos modos de ver hoje, articulando um mergulho nas imagens da mídia, nos discursos que ela faz circular e nos modos de subjetivação que eles incitam" (FISCHER, 2002, p. 91).

\section{REFERÊNCIAS}

DEBORD, G. A sociedade do espetáculo. Rio de Janeiro: Contraponto, 1997.

FISCHER, R. M. B. Televisão \& educação: fruir e pensar a TV. Belo Horizonte: Autêntica, 2001.

. Problematizações sobre o exercício de ver: mídia e pesquisa em educação.

Revista Brasileira de Educação, Anped, São Paulo: Autores Associados , n. 20, p. 83-94, maio/ago. 2002.

GAARDER, J.; HAGERUP, K. A biblioteca mágica de Bibbi Bokken. São Paulo: Companhia das Letras, 2003.

KEHL, M. R. Televisão e violência do imaginário. In: BUCCI, E.; KEHL, M. R. Videologias - ensaios sobre televisão. São Paulo: Boitempo, 2004. p. 87-106.

SCHWERTNER, S. F. O laço fraterno em Cidade dos Homens: articulações entre Educação, Psicanálise e Comunicação. Porto Alegre, 2005. Dissertação (Mestrado em Educação) - Programa de Pós-Graduação em Educação, Universidade Federal do Rio Grande do Sul.

SONTAG, S. Diante da dor dos outros. São Paulo: Companhia das Letras, 2003.

VANUCCHI, C. Comédia da Vida Real. IstoÉ, n. 1814, p. 59, 14 jul. 2004.

ZIZEK, S. Bem-vindo ao deserto do Real!: cinco ensaios sobre o 11 de setembro e datas relacionadas. São Paulo: Boitempo, 2003.

Texto recebido em 14 jan. 2005 Texto aprovado em 15 maio 2005 